\title{
Improvement in Quality of Life, Functional Capacity, and Depression Level after Cardiac Rehabilitation
}

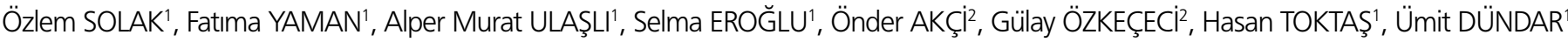 \\ ${ }^{1}$ Department of Physical Medicine and Rehabilitation, Afyon Kocatepe University Faculty of Medicine, Afyonkarahisar, Turkey \\ ${ }^{2}$ Department of Cardiology, Afyon Kocatepe University Faculty of Medicine, Afyonkarahisar, Turkey
}

\begin{abstract}
Objective: In cardiac rehabilitation program (CRP), patients are supported to achieve and maintain optimal physical and psychosocial health following a recent cardiac event or procedure. In this study, we aimed to retrospectively assess the effects of CRP in our cardiopulmonary rehabilitation unit.

Material and Methods: Records of 40 patients with a diagnosis of coronary artery disease (CAD) and 10 patients who had undergone coronary artery bypass graft surgery (CABG) and who completed 30 sessions were evaluated. CRP comprised aerobic exercise with cycle ergometer and the upper and lower extremity strengthening exercises. The patients' vital signs were monitored during the cycle ergometer exercise. The quality of life of the patients were evaluated with the Short Form-36 (SF-36), aerobic exercise capacity and metabolic equivalent (MET) levels were assessed with the effort test using the Bruce protocol, their functional capacity was assessed with a 6-min walk test, and depression levels were assessed with the Beck Depression Inventory.

Results: After CRP, there were statistically significant differences in all subunits of SF-36 except social function, emotional role, and mental component in patients with $C A D(p \leq 0.05)$. In patients with $C A B G$, physical function, physical role, social function, and mental health subunits of SF-36 significantly improved $(p \leq 0.05)$. The patients' mean MET values significantly increased in both the groups $(p \leq 0.05)$. The mean 6-MWT distances significantly increased from $455.3 \pm 66.4$ to $522.7 \pm 68.5 \mathrm{~m}$ after CRP in patients with CAD $(p<0.001)$. Furthermore, in patients with CABG, the mean 6-MWT distances significantly increased from $389.1 \pm 88.5$ to $495.0 \pm 99.1 \mathrm{~m}(\mathrm{p} \leq 0.05)$. There was significant decrease in BDI score from $4.3 \pm 7.1$ to $2.9 \pm 4.3$ in patients with $C A D(p \leq 0.05)$. However, no significant change in mean BDI score was observed in patients with CABG.

Conclusion: In our cardiopulmonary rehabilitation unit, CRP, comprising endurance exercise using cycle ergometer, improved the quality of life and functional capacity in patients with CAD and CABG. However, the improvement in depression level was observed only in patients with CAD.

Keywords: Cardiac rehabilitation, endurance exercise, cycle ergometer
\end{abstract}

\section{Introduction}

Physical exercise is an important component of the standard therapy for patients after a cardiac event (1). The World Health Organization has defined secondary prevention cardiac rehabilitation (CR) as "the sum of activities required to favorably influence the underlying cause of the disease as well as the best possible physical, mental, and social conditions so that they may, by their own efforts, preserve or resume as normal a place as possible in the community (WHO, 1993.p.3). Rehabilitation cannot be regarded as an isolated form of therapy but must be integrated with the whole treatment of which it forms only one facet (2). Clinical trials demonstrate significant reductions in allcause and cardiovascular mortality for patients with coronary artery disease (CAD) who are enrolled in exercise-based cardiac rehabilitation programs $(3,4)$.

However, quality of life (QoL) outcomes of CR have attracted less attention. Health-related QoL (HRQoL) represents the

Address for Correspondence: Özlem Solak, MD, Afyon Kocatepe Üniversitesi Tıp Fakültesi, Fiziksel Tıp ve Rehabilitasyon Anabilim Dalı, Afyonkarahisar, Türkiye. Phone: +90272 2463304 E-mail: ozlemsolak@hotmail.com

Received: January 2014 Accepted: May 2014

oCopyright 2015 by Turkish Society of Physical Medicine and Rehabilitation - Available online at www.ftrdergisi.com

Cite this article as: 
patient's own evaluation of the impact of a disease on his/her physical function and wellbeing (5).

Several instruments for assessing HRQoL have been developed, both generic and disease specific. HRQoL assessments have been evaluated in a recent review, and the results suggest that the Short Form 36 (SF-36) is the most appropriate generic measure of HRQoL among people with ischemic heart disease $(6,7)$.

The positive effect of CR on functional capacity has long been revealed $(8,9)$. The 6 -min walk test is widely used to assess functional capacity and prognosis (10).

Depression is common after coronary artery bypass graft ( $C A B G)$ surgery, in patients with CAD and chronic heart failure and is associated with poor QoL, increased morbidity, frequency of hospitalizations, and mortality. Research suggests that depression in populations with CABG and CAD improves during exercise training rehabilitation programs (11).

In our retrospective study, we aimed to determine changes in QoL, depression level, and functional capacity of patients with CAD and $C A B G$ who attended an outpatient rehabilitation program.

\section{Material and Methods}

A retrospective analysis was performed for 50 outpatients enrolled in the cardiac rehabilitation program (CRP) from November 2011 to May 2013 in Afyon Kocatepe University Hospital Department of Physical Medicine and Rehabilitation. We obtained the ethics committee's approval and informed consent from the patients. The charts of patients who had completed 30 sessions of $C R$ were reviewed. Forty patients with a diagnosis of $C A D$ and 10 patients who had undergone CABG were included in the study. CRP comprised 5 min of warm-up, $10 \mathrm{~min}$ of range of motion, 10 min of strengthening, 30 min of aerobic exercise with cycle ergometer, and 5 min of cool-down exercises. The patients' vital signs, including pulse, tension arterial, heart rhythm, and oxygen saturation, were monitored during the cycle ergometer exercise (Ergoselect 200, Ergoline $\mathrm{GmbH}$, Bitz, Germany). All patients exercised with a constant heart rate training program.

The QoL was assessed using SF-36, a generic HRQoL questionnaire. It comprises 36 questions grouped in eight separate multi-item scales, covering the following domains: physical functioning (10 items), role limitations due to physical problems (four items), body pain (four items), general health perception (five items), vitality (four items), social functioning (two items), role limitations due to emotional problems (three items), and mental health (five items). Majority of the scales are scored on three- to six-point categorical scales with different anchor points, whereas the response choices in the role functioning scales are dichotomous (6). The questions were summated and transformed to eight 0-100 scales with higher scores indicating better HRQoL. The Turkish version has been proved to be valid and reliable (12).

The 6-min walk test (6-MWT) is a practical simple test that requires a $100-\mathrm{ft}$ hallway but no exercise equipment or advanced training for technicians. This test measures the distance that a patient can quickly walk on a flat, hard surface in a period of $6 \mathrm{~min}$. It evaluates the global and integrated responses of all the systems involved during exercise, including the pulmonary and cardiovascular systems, systemic circulation, peripheral circulation, blood, neuromuscular units, and muscle metabolism. Functional capacity of patients was assessed with 6-MWT (13).

Table 1. Demographics of patients with CAD and CABG undergoing CRP

\begin{tabular}{lcc} 
& CAD $(n=40)$ & CABG $(n=10)$ \\
\hline Age (years) (Mean \pm SD) & $55.9 \pm 8.4$ & $58.7 \pm 4.7$ \\
Male/Female $(n)$ & $35 / 5$ & $9 / 1$ \\
Diagnosis duration (months) & $17.6 \pm 23.4$ & $59.1 \pm 53.7$ \\
\hline
\end{tabular}

CAD: coronary artery disease; CABG: coronary artery bypass graft; CRP: cardiac rehabilitation program; SD: standard deviation

Table 2. Pre-CR and Post-CR SF-36 subunit values of patients with CAD

\begin{tabular}{lccc} 
& $\begin{array}{c}\text { Pre-CR } \\
(\text { Mean } \pm \text { SD })\end{array}$ & $\begin{array}{c}\text { Post-CR } \\
(\text { Mean } \pm \text { SD })\end{array}$ & p value \\
\hline Physical function & $61.9 \pm 26.1$ & $75.7 \pm 20.8$ & 0.00 \\
Physical role & $48.0 \pm 39.8$ & $65.1 \pm 38.7$ & 0.002 \\
Pain & $63.7 \pm 24.8$ & $73.8 \pm 21.6$ & 0.007 \\
General health & $55.8 \pm 17.5$ & $69.7 \pm 19.8$ & 0.00 \\
Vitality & $59.5 \pm 21.5$ & $69.4 \pm 20.9$ & 0.002 \\
Social function & $71.2 \pm 23.2$ & $77.9 \pm 21.4$ & 0.061 \\
Emotional role & $53.3 \pm 40.5$ & $64.9 \pm 35.4$ & 0.066 \\
Mental health & $63.9 \pm 21.2$ & $71.9 \pm 19.4$ & 0.003 \\
Physical component & $42.4 \pm 9.8$ & $47.5 \pm 8.6$ & 0.00 \\
Mental component & $45.8 \pm 9.9$ & $48.4 \pm 8.8$ & 0.057
\end{tabular}

Pre-CR: pre-cardiac rehabilitation; Post-CR: post-cardiac rehabilitation; CAD: coronary artery disease; SF-36: Short form 36; SD: standard deviation

Table 3. Pre-CR and Post-CR SF-36 subunit values of patients with CABG

\begin{tabular}{lccc} 
& $\begin{array}{c}\text { Pre-CR } \\
(\text { Mean } \pm \text { SD) }\end{array}$ & $\begin{array}{c}\text { Post-CR } \\
(\text { Mean } \pm \text { SD })\end{array}$ & p value \\
\hline Physical function & $45.2 \pm 19.1$ & $61.5 \pm 20.6$ & 0.028 \\
Physical role & $18.5 \pm 23.1$ & $60.0 \pm 35.7$ & 0.011 \\
Pain & $52.4 \pm 19.7$ & $60.9 \pm 27.2$ & 0.343 \\
General health & $35.6 \pm 21.5$ & $46.3 \pm 26.2$ & 0.206 \\
Vitality & $47.0 \pm 19.0$ & $55.0 \pm 24.0$ & 0.076 \\
Social function & $70.0 \pm 23.7$ & $81.2 \pm 12.1$ & 0.038 \\
Emotional role & $39.3 \pm 30.1$ & $46.6 \pm 39.1$ & 0.273 \\
Mental health & $53.0 \pm 17.3$ & $62.8 \pm 19.4$ & 0.011 \\
Physical component & $35.5 \pm 6.2$ & $40.8 \pm 9.2$ & 0.114 \\
Mental component & $40.7 \pm 8.6$ & $44.3 \pm 6.6$ & 0.241 \\
\hline
\end{tabular}

Pre-CR: pre-cardiac rehabilitation; Post-CR: post-cardiac rehabilitation; SD: standard deviation 
Table 4. Pre-CR and Post-CR MET values, 6-MWT distances and BDI scores of patients with CAD and CABG

\begin{tabular}{|c|c|c|c|c|c|c|}
\hline & $\begin{array}{c}\text { Pre-CR } \\
(\text { Mean } \pm S D)\end{array}$ & $\begin{array}{c}\text { Post-CR } \\
(\text { Mean } \pm S D)\end{array}$ & ${ }^{*} p$ value & $\begin{array}{c}\text { Pre-CR } \\
(\text { Mean } \pm S D)\end{array}$ & $\begin{array}{c}\text { Post-CR } \\
(\text { Mean } \pm \text { SD) }\end{array}$ & ${ }^{* *} p$ value \\
\hline MET value & $9.9 \pm 2.1$ & $10.9 \pm 1.9$ & 0.000 & $7.9 \pm 1.1$ & $9.3 \pm 1.8$ & 0.007 \\
\hline 6-MWT (m) & $455.3 \pm 66.4$ & $522.7 \pm 68.5$ & 0.000 & $389.1 \pm 88.5$ & $495.0 \pm 99.1$ & 0.005 \\
\hline BDI score & $4.3 \pm 7.1$ & $2.9 \pm 4.3$ & 0.021 & $6.0 \pm 5.6$ & $5.7 \pm 7.8$ & 0.344 \\
\hline
\end{tabular}

${ }^{*} p$ value for patients with CAD

${ }^{* *} \mathrm{p}$ value for patients with CABG

6-MWT: six-min walk test; BDI: Beck Depression Inventory; Pre-CR: pre-cardiac rehabilitation; Post-CR: post-cardiac rehabilitation; CAD: coronary artery disease; CABG: coronary artery bypass graft surgery; MET: metabolic equivalent; SD: standard deviation

It is convenient to express the oxygen uptake in multiples of resting requirement. The metabolic equivalent (MET) is a unit of resting oxygen uptake. Rather than using each the patient's own value, one MET is designated as the average value (3.5 $\mathrm{mL} \mathrm{O}$ uptake $/ \mathrm{kg} / \mathrm{min}$ ). A mean exercise capacity of 10 METs has been observed in nonathletic, healthy, middle-aged men (14).

Effort stress tests of patients were performed before and after the rehabilitation program to determine the changes in MET values.

Beck Depression Inventory (BDI) was used to determine depression level. BDI is a 21-question multiple-choice self-reported inventory, one of the most widely used method, for measuring depression severity. When the test is scored, a value of $0-3$ is assigned for each answer and then the total score is compared with a key to determine the depression's severity. The standard cut-offs are as follows: 0-9, indicates minimal depression; 10-18, indicates mild depression; 19-29, indicates moderate depression; and 30-63, indicates severe depression. Higher total scores indicate more severe depressive symptoms (15).

\section{Statistical Analysis}

Statistical analyses were performed using SPSS version 15.0 (Statistical Package for the Social Sciences Inc., Chicago, IL, USA). Descriptive statistics and means were used to describe the features of the data. The normality of the distribution of continuous variables was assessed with the Kolmogorov-Simirnov test. To compare the outcome measures obtained before and after $\mathrm{CR}$, Wilcoxon signed rank test or paired samples T-test were used where appropriate. A $p$ value of $<0.05$ was considered to demonstrate a statistically significant result.

\section{Results}

The demographics of patients are depicted in Table 1. The mean age of patients with $C A D$ and $C A B G$ were $55.9 \pm 8.4$ and $58.7 \pm 4.7$ years, respectively. Seven $(17.5 \%)$ patients with CAD and two (20\%) patients with CABG never smoked.

There were statistically significant differences in all subunits of SF-36 except social function, emotional role, and mental component after CRP in patients with CAD $(p \leq 0.05)$ (Table
2). In patients with $C A B G$, physical function, physical role, social function, and mental health subunits of SF-36 significantly improved $(\mathrm{p} \leq 0.05)$ (Table 3$)$.

The mean 6-MWT distances significantly increased from $455.3 \pm 66.4$ to $522.7 \pm 68.5 \mathrm{~m}$ after CRP in patients with CAD $(p<0.001)$. Moreover, in patients with $C A B G$, the mean 6-MWT distances significantly increased from $389.1 \pm 88.5$ to

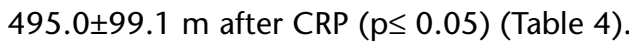

The mean MET value significantly changed after CRP in both patients with CAD and CABG $(p<0.05)$ (Table 3$)$.

There was significant decrease in BDI score from 4.3 \pm 7.1 to $2.9 \pm 4.3$ after CRP in patients with CAD $(p \leq 0.05)$. However, we did not observe significant change in the mean BDI score in patients with CABG ( $p>0.05)$ (Table 3).

\section{Discussion}

In this study, we demonstrated that cardiac rehabilitation program, comprising 30 sessions of exercise training, is associated with significant improvements in the QoL and functional capacity for outpatients with CAD and CABG. However, the depression level significantly improved only in patients with CAD.

As an outcome in an intervention like CR where the objective is for patients "by their own efforts, to preserve or resume as normal a place as possible in the community," physical and psychological well-being; that is, HRQoL may be as important to a patient as survival (2). Hsu et al. (16) reported an effect of outpatient CR on HRQoL among patients who underwent aortic coronary bypass. After the end of rehabilitation, there were significant improvements in physical functioning, physical role, bodily pain, and social function among these patients. Karapolat et al. (17) compared the effects of hospital-supervised exercise vs. home-based exercise in patients after orthotopic heart transplantation on functional capacity, QoL, and psychological symptoms and reported significant improvements in pVO2 and most SF-36 subgroups in the hospital-based exercise group. In accordance with these findings, we observed significant improvement in QoL in patients with CABG. Furthermore, Stauber et al. (18) reported significant improvements in all subunits of SF-36 in 520 patients with coronary artery after a comprehensive 12-week outpatient CRP. Moreover, in our study, the QoL of patients with CAD significantly improved after 30 sessions of outpatient CRP. 
Many patients in contemporary cardiac rehabilitation programs are quite deconditioned on entry. Using the 6-MWT to assess submaximal exercise capacity, for example, patients walked an average of only $76 \pm 21 \%$ of the 6 -min walk distance predicted for their age, sex, height, and weight; mean distance walked at the completion of CR was $90 \pm 22 \%$ predicted and the proportions of patients performing at $\geq 80 \%$ of predicted walk distance increased from $44 \%$ to $69 \%(19,20)$. Stahle et al. (21) reported $15 \%$ improvement that was observed in the 6-MWT distances in elderly patients with post-myocardial infarction after an aerobic-based exercise intervention. Karapolat et al. (22) compared hospital-based vs. home-based exercise training in patients with heart failure and reported significant improvement in $\mathrm{pVO}_{2}$ and 6-MWT in both the groups. Freyssin et al. (23) observed significant increase in the distance walked during the 6MWT in 26 patients with chronic heart failure after both continuous and interval training cardiac rehabilitation program lasting for 8 weeks. Jelinek et al. (24) reported that a 6-week cardiac rehabilitation program improves 6-MWT in both patients who had undergone CABG and percutaneous coronary revascularization. In this study, they compared 6-MWT distances before and after 6-week of CRP and found improvements in both the groups. In accordance with the literature, we determined improvement in 6-MWT distances for patients with $C A B G$ and CAD in our study.

Improving depression was not a specific target of cardiac rehabilitation. However, the rehabilitation program confers a high amount of physical exercise that may be expected to alleviate depressive symptoms in its own right (25). Stauber et al. (18) reported significant improvements in depression and anxiety levels after a 12-week cardiac rehabilitation program, comprising aerobic endurance, strength training and relaxation sessions, for patients with CAD. In a study by Milani and Lavie (26), depressive symptoms were assessed by a questionnaire, and mortality was evaluated at 40 months in over 500 consecutive coronary patients completing vs. not completing rehabilitation. Decreased depressive symptoms and decreased mortality were associated with improved fitness with only the modest improvement in fitness levels required to produce these benefits. In our study, we also observed significant improvement in depression levels of patients with CAD after 30 sessions of outpatient CRP. In another study by Karapolat et al. (27), the efficacy of the cardiac rehabilitation program in patients with end-stage heart failure, heart transplant patients and left ventricular assist device recipients, they demonstrated significant improvement in functional capacity, pulmonary function test, QoL, and depression after an 8-week supervised exercise program. Kulcu et al. (28) assessed the effect of cardiac rehabilitation on depression in patients with congestive heart failure and reported significant improvement in BDI scores in the treatment group in the short term. Sharif et al. (29) observed significant decreases in BDI scores in 80 patients with $C A B G$ at the end of and 2 months after the 32 sessions of cardiac rehabilitation exercise program. However, in this study, we could not demonstrate improvement in the depression level of CABG after the 30 sessions of outpatient CRP. This may be because of the small number of patients with CABG attending this program.

The exercise tolerance test (ETT) can provide important prognostic information. Cardiac rehabilitative exercise training improves these ETT-derived prognostic variables and decrease predicted cardiovascular risk scores that incorporate these variables (30). Among men with and without cardiovascular disease who were referred for treadmill exercise testing, peak exercise capacity measured in METS was the strongest predictor of the risk of death, during an average of 6.2 years followup (14). For each MET increase in exercise capacity, there was a $12 \%$ improvement in survival.

Adams et al. (30) reported significant increase in MET values after a supervised CR program in 210 patients with CAD in a retrospective study. Rechcinski et al. (31) demonstrated significant increase in MET values after early cardiac rehabilitation program for patients following complete revascularization and incomplete revascularization by $\mathrm{PCI}$. In a study, the effect of CRP on exercise capacity in women undergoing CABG was investigated, and significant increases of estimated exercise capacity in terms of MET values were reported (32). In our study, we observed improvement in MET values after CRP in patients with CAD in accordance with the literature.

This study had several limitations. First, the number of patients with CABG and CAD were relatively low. Second, because the study was retrospective and did not include a control group, we were unable to compare the effectiveness of CRP over home-based exercise. Furthermore, as spontaneous improvement may occur in aerobic capacity in the following several weeks in patients with CHD who have not received an exercise-based CR, the lack of control group in our study limits us to make assertive conclusions regarding our results.

Therefore, to our knowledge, our study is among the first retrospective studies reporting the effect of 30 sessions of CRP comprising 30 sessions of endurance training using only the cycle ergometer with constant heart rate program in our country.

\section{Conclusion}

This retrospective study, involving 40 patients with $C A D$ and 10 patients with $C A B G$, demonstrated that outpatient $C R$ program, comprising 30 sessions of endurance and strengthening exercises, provides improvements in the QoL and functional capacity of both patients with CAD and CABG. Therefore, with this CRP, only patients with CAD could gain improvement in depression level. This may be because of the small number of patients with $C A B G$. However, feature prospective and controlled studies with longer follow-up and large sample size are required to support our findings. 
Ethics Committee Approval: Ethics committee approval was received for this study from the ethics committee of Afyonkarahisar Medical Research Ethics Committee (Number: 2014/16).

Informed Consent: Verbal informed consent was obtained from patients who participated in this study.

Peer-review: Externally peer-reviewed.

Author Contributions: Concept - Ö.S.; Design - F.Y.; Supervision - G.Ö.; Resource - Ö.A.; Materials - H.T.; Data Collection and/or Processing - F.Y.; Analysis and/or Interpretation - A.M.U.; Literature Review - S.E.; Writer - Ö.S.; Critical Review - Ü.D.

Conflict of Interest: No conflict of interest was declared by the authors.

Financial Disclosure: The authors declared that this study has received no financial support.

\section{References}

1. Ades PA. Medical progress: cardiac rehabilitation and secondary prevention of coronary artery disease. N Eng J Med 2001;345:892902. [CrossRef]

2. World Health Organization Expert Committee On Rehabilitation: rehabilitation after cardiovascular diseases, with special emphasis on developing countries: report of a WHO Committee. World Health Organ Tech Rep Ser 1993;831:1-122.

3. Oldridge NB, Guyatt GH, Fischer ME, Rimm AA. Cardiac rehabilitation after myocardial infarction: combined experience of randomized clinical trials. JAMA 1988;260:945-50. [CrossRef]

4. O'Connar GT, Buring JE, Yusuf S, Goldhaber SZ, Olmstead EM, Paffenbarger RS JR, et al. An overview of randomized trials of rehabilitation with exercise after myocardial infarction. Circulation 1989;80:234-44. [CrossRef]

5. Shepherd CW, While AE. Cardiac rehabilitation and quality of life: a systematic review. Int J Nurs Stud 2012;49:755-71. [CrossRef]

6. Ware JE Jr. SF-36 health survey update. Spine 2000;25:3130-39. [CrossRef]

7. Dempster M, Donnelly M. Measuring the health related quality of life of people with ischaemic heart disease. Heart 2000;83:641-4. [CrossRef]

8. Yohannes AM, Doherty P, Bundy C, Yalfani A. The long-term benefits of cardiac rehabilitation on depression, anxiety, physical activity and quality of life. J Clin Nurse 2010;19:2806-13. [CrossRef]

9. Listerman J, Bittner V, Sanderson BK, Brown TM. Cardiac rehabilitation outcomes: impact of comorbidities and age. J Cardiopulm Rehabil Prev 2011;31:342-8. [CrossRef]

10. Bittner V. Six-minute walk test in patients with cardiac dysfunction. Cardiologia 1997;42:897-902.

11. Blumenthal JA, Babyak MA, O'Connor C, Keteyian S, Landzberg J, Howlett J, et al. Effects of exercise training on depressive symptoms in patients with chronic heart failure: the HF-ACTION randomized trial. JAMA 2012;308:465-74. [CrossRef]

12. Koçyiğit H, Aydemir Ö, Fişek $G$, Ölmez N, Memiş A. Kısa Form-36 (KF-36)'nın Türkçe versiyonunun güvenilirliği ve geçerliliği. Ilaç ve Tedavi Dergisi 1999;12:102-6.

13. Robertson LD, Ewing AS, Bentley BJ. American thoracic society statement: Guidelines fort he six-minute walk test. Guidelines for pulmonary rehabilitation programs. Human Kinetics 2004;127-8.

14. Myers J, Prakash M, Froelicher V, Do D, Partington S, Atwood JE. Exercise capacity and mortality among men referred for exercise testing. N Engl J Med 2002;346:793-801. [CrossRef]
15. Beck AT, Steer RA, Garbin MG J. Psychometric properties of the Beck Depression Inventory twenty-five years of evaluation. Clin Psych 1988;8:77-100. [CrossRef]

16. Hsu C], Chen SY, Su S, Yang MC, Lan C, Chou NK, et al. The effect of early cardiac rehabilitation on health-related quality of life among heart transplant recipients and patients with coronary artery bypass graft surgery. Transplant Proc 2011;43:2714-7. [CrossRef]

17. Karapolat H, Eyigör S, Zoghi M, Yagdi T, Nalbangil S, Durmaz B. Comparison of hospital-supervised exercise versus home-based exercise in patients after orthotopic heart transplantation: effects on functional capacity, quality of life, and psychological symptoms. Transplant Proc 2007;39:1586-8. [CrossRef]

18. Stauber S, Guéra V, Barth J, Schmid JP, Saner H, Znoj H, et al. Psychosocial outcome in cardiovascular rehabilitation of peripheral artery disease and coronary artery disease patients. Vasc Med 2013; 18:257-62. [CrossRef]

19. Sanderson BK, Schumann C, Breland J, Williams N, Saunders K, Bittner V. Six-minute walk assessment in cardiac rehabilitation: is there a standard for functional performance? Med Sci Sport 2005;37:1186. [CrossRef]

20. Enright PL, Sherrill DL. Reference equations for the six-minute walk in healthy adults. Am J Resp Crit Care Med 1998;158:1384-7. [CrossRef]

21. Stahle A, Mattson E, Ryden L, Unden A, Nordlander R. Improved physical fitness and quality of life following training of elderly patients after acute coronary events: a 1 year follow-up randomized controlled study. Eur Heart J 1999;20:1475-84. [CrossRef]

22. Karapolat H, Demir E, Bozkaya YT, Eyigör S, Nalbantgil S, Durmaz $\mathrm{B}$, et al. Comparison of hospital-based versus home-based exercise training in patients with heart failure: effects on functional capacity, quality of life, psychological symptoms, and hemodynamic parameters. Clin Res Cardiol 2009;98:635-42. [CrossRef]

23. Freyssin C, Verkindt C, Prieur F, Benaich P, Maunier S, Blanc P. Cardiac rehabilitation in chronic heart failure: effect of an 8-week, highintensity interval training versus continuous training. Arch Phys Med Rehabil 2012;93:1359-64. [CrossRef]

24. Jelinek HF, Huang ZQ, Khandoker AH, Chang D, Kiat H. Cardiac rehabilitation outcomes following a 6- week program of $\mathrm{PCl}$ and CABG patients. Front Physiol 2013;4:302. [CrossRef]

25. Blumenthal JA, Sherwood A, Babyak A, Watkins LL, Smith PJ, Hoffman $B M$, et al. Exercise and pharmacological treatment of depressive symptoms in patients with coronary heart disease. J Am Coll Cardiol 2012;18:1053-63.

26. Milani RV, Lavie CJ. Impact of cardiac rehabilitation on depression and its associated mortality. Am J Med 2007;120:799-806. [CrossRef]

27. Karapolat H, Engin C, Eroğlu M, Yağdı T, Zoghi M, Nalbantgil S, et al. Efficacy of cardiac rehabilitation program in patients with end-stage heart failure, heart transplant patients, and left ventricular assist device recipients. Transplant Proc 2013;45:3381-5. [CrossRef]

28. Kulcu DG, Yurtais Y, Tur BS, Gülec S, Seckin B. The effect of cardiac rehabilitation on quality of life, anxiety and depression in patients with congestive heart failure. A randomized controlled trial, shortterm results. Eura Medicophys 2007;43:489-97.

29. Sharif F, Shoul A, Janati M, Kojuri J, Zare N. The effect of cardiac rehabilitation on anxiety and depression in patients undergoing cardiac bypass graft surgery in Iran. BMC Cardiovasc Disord 2012;12:40. [CrossRef] 
30. Adams BJ, Carr JG, Ozonoff A, Lauer MS, Balady GJ. Effect of exercise training supervised cardiac rehabilitation programs on prognostic variables from the exercise tolerance test. Am J Cardiol 2008;101:1403-7. [CrossRef]

31. Rechcinski T, Kalowski M, Kasprzak JD, Trzos E, Kurpesa M. Beneficial effects of cardiac rehabilitation in patients with incomplete revascularization after primary coronary angioplasty. Eur J Phys Rehabil Med 2013;49:785-91.

32. Shabani R, Gaeini AA, Nikoo MR, Nikbackt $H$, Sadegifar M. Effect of cardiac rehabilitation program on exercise capacity in women undergoing coronary artery bypass graft in Hamadan-Iran. Int J Prev Med 2010;1:247-51. 